\title{
Tendências no ensino da matemática nos anos finais do ensino fundamental: abordagens evidenciadas em livros didáticos
}

\author{
Trends in teaching mathematics in the final years of elementary school: approaches \\ evidenced in textbooks
}

\author{
Adriana Richit \\ adrianarichit@gmail.com \\ Luana Angélica Alberti \\ luana.albertti@yahoo.com.br
}

\begin{abstract}
Resumo
O artigo problematiza o modo como são abordadas as principais tendências no ensino de matemática em livros didáticos dos anos finais do ensino fundamental. A análise seguiu a perspectiva qualitativa e interpretativa, baseada em uma análise de conteúdo bardiniana, e tomou por foco de investigação a coleção Praticando Matemática, do $6 .^{\circ}$ ao $9 .^{\circ}$ ano, que foi a coleção com maior número de exemplares distribuídos na segunda edição do Programa Nacional do Livro Didático (no triênio 2014-2016), posterior à implementação do ensino fundamental de nove anos. Mediante a análise realizada foram evidenciadas três perspectivas, segundo as quais as tendências no ensino da matemática têm sido desenvolvidas: abordagem histórica para apresentação e/ou desenvolvimento de conteúdos matemáticos, possibilitando a percepção de que a matemática é uma criação humana situada num tempo e espaço dinâmico, que surge a partir de necessidades sociais humanas; situações matemáticas como contexto para o desenvolvimento de conteúdos matemáticos, buscando aproximar a matemática escolar da matemática da sociedade e; situações investigativas como cenário de aprendizagem da matemática, as quais se constituem em atividades que oportunizem aos alunos participar na construção do conhecimento.
\end{abstract}

Palavras-chave: Tendências no ensino da matemática; Ensino fundamental de nove anos; Livros didáticos de matemática; Anos finais do ensino fundamental.

\begin{abstract}
The paper problematizes how the principal trends in the mathematic teaching have been approached in textbook of the elementary school final years. The analyses persecuted a research qualitative and interpretative approach and it based in the Bardin' contend analysis realized about the mathematic' textbooks collection named Practicing Mathematic, $6^{\text {th }}$ to $9^{\text {th }}$ school years. This collection had the most number of books distributed in the second edition of National Program of Textbook, which was implemented in the 2014-2016, subsequent to implementation of nine years' elementary school. From the analyses we evidenced three perspectives about the ways by which the mathematic teaching tends have been developed in the mathematics' textbooks: historical approach to presentation and/or mathematical contend development, promoted the perception that the mathematic is a human creation situated in a dynamic time and space, developed from humans social necessities; mathematical situations taken as context to mathematical contend development, seeking closer scholar math and social math; investigative situations as scenario to mathematical learning which constitute activities in that the students have opportunity to participate in the process of knowledge construction.
\end{abstract}

Key words: Trends in the mathematic teaching; Elementary school; Textbooks of mathematic; Elementary school final years.

\section{Introdução}

Ter acesso aos materiais didáticos necessários aos processos de ensino e aprendizagem, sobretudo livros didáticos, é direito assegurado a todo aluno da Educação 
Básica e da Educação de Jovens e Adultos de escolas públicas brasileiras, as quais estejam cadastradas no censo escolar do Instituto Nacional de Estudos e Pesquisas Educacionais Anísio Teixeira (Inep) ${ }^{1}$ e vinculadas ao Programa Nacional do Livro Didático (PNLD). Segundo o Decreto n. ${ }^{\circ}$ 7.084, de 27 de janeiro de 2010, por meio dos materiais distribuídos pelo PNLD, que são custeados pelo Fundo Nacional de Desenvolvimento da Educação $(\mathrm{FNDE})^{2}$, busca-se, entre outras metas, atender ao preceito constitucional da melhoria da qualidade e desenvolvimento do ensino.

Dentre as principais iniciativas do poder público na busca pela melhoria da qualidade da educação pública, destacam-se as mudanças ocorridas nos programas do livro didático que deram origem, em 1985, ao PNLD.

Em face da abrangência do PNLD e de outras ações relacionadas ao provimento de materiais didáticos às escolas públicas brasileiras, os livros didáticos constituem-se no principal recurso educacional, fazendo-se presentes nos ambientes escolares em todo o país. No que diz respeito ao livro didático de matemática, embora esteja muito presente nos processos de ensino e aprendizagem nas diferentes etapas escolares, este recurso, ao longo do tempo, tem sido alvo de críticas, principalmente quanto a sua estrutura, sobre a qual alega-se descontextualização dos conteúdos, apresentação de atividades que solicitam dos alunos apenas a reprodução de procedimentos de solução padronizados, a falta de relação entre um conteúdo e outro, etc. (ROMANATTO, 2004; OLIVEIRA, 2007). Ainda, aos livros didáticos de matemática tem sido atribuída a responsabilização por determinarem o currículo dos anos escolares, pois tem se observado em vários contextos que "os conteúdos escolares, assim como os princípios metodológicos passaram a ser veiculados pelos livros didáticos" (ROMANATTO, 2004, p. 2).

Entretanto, parte dos aspectos criticados nos livros didáticos de matemática têm sido retomados, mais especificamente a partir do PNLD do ano de 2011, em função das modificações que se fizeram necessárias na organização destes materiais com a

\footnotetext{
${ }^{1}$ O Inep é uma "autarquia federal vinculada ao Ministério da Educação (MEC), cuja missão é promover estudos, pesquisas e avaliações sobre o Sistema Educacional Brasileiro com o objetivo de subsidiar a formulação e implementação de políticas públicas para a área educacional a partir de parâmetros de qualidade e equidade, bem como produzir informações claras e confiáveis aos gestores, pesquisadores, educadores e público em geral”. Disponível em: <http://portal.inep.gov.br/conheca-o-inep>. Acesso em: 24 set. 2015.

${ }^{2}$ O FNDE “autarquia federal criada pela Lei n. ${ }^{\circ}$ 5.537, de 21 de novembro de 1968, e alterada pelo Decreto-Lei $\mathrm{n}^{\circ} 872$, de 15 de setembro de 1969, é responsável pela execução de políticas educacionais do Ministério da Educação (MEC)" captando e distribuindo recursos financeiros a vários programas do ensino. Disponível em: $<$ http://www.fnde.gov.br/fnde/institucional >. Acesso em: 24 set. 2015.
} 
implementação do ensino fundamental de nove anos, entre 2006 e 2010, que veio consolidar a reestruturação da educação básica no Brasil.

No que diz respeito à reestruturação do ensino fundamental, a Lei n. ${ }^{\circ}$ 11.274, de fevereiro de 2006, que alterou o artigo 32 da Lei de Diretrizes e Bases da Educação Nacional, estabelece que o ensino fundamental, obrigatório e gratuito em escolas públicas, passa a ter duração de nove anos, iniciando-se aos seis anos de idade (BRASIL, 2006). O artigo $5 .^{\circ}$ da referida Lei estabeleceu, ainda, que a reestruturação deveria ocorrer progressivamente, consolidando-se até o ano 2010.

Assim, o ensino fundamental, reorganizado em anos iniciais (com duração de cinco anos e ingresso aos seis anos de idade) e anos finais (com duração de quatro anos) teve sua estrutura profundamente alterada, implicando mudanças em nível de currículo, de organização escolar, de práticas pedagógicas e recursos didáticos, tais como livros didáticos. As mudanças decorrentes desta determinação abarcaram, inclusive, a estrutura e apresentação dos livros didáticos destinados a este nível de escolaridade.

Além disso, considerando que os livros didáticos, elaborados antes e depois da reestruturação do ensino fundamental, têm sido reorganizados em consonância com as orientações dos Parâmetros Curriculares Nacionais $(\mathrm{PCN})^{3}$, observa-se que diversas tendências ${ }^{4}$ no ensino da matemática, como história da matemática, resolução de problemas, tecnologias, jogos matemáticos, vêm sendo incorporadas a estes materiais, com o objetivo de melhorar o ensino e, especialmente, a aprendizagem matemática dos alunos.

Dentre as tendências no ensino da matemática sugeridas nos PCN estão: a resolução de problemas, indicada como ponto de partida à atividade matemática; a história da matemática, entendida como abordagem que propicia uma compreensão da trajetória dos conceitos e métodos da matemática; as tecnologias da comunicação, concebidas como um dos principais elementos de transformação da sociedade, que estão cada vez mais presentes nas

3 Os PCN são referenciais que apresentam conteúdos básicos de ensino, bem como objetivos e orientações metodológicas que podem nortear o trabalho docente. Estes referenciais foram elaborados pelo Governo Federal durante o primeiro mandato do presidente Fernando Henrique Cardoso (1995-1998) e não pelo Conselho Nacional de Educação, que é o órgão normativo da educação. Estes materiais foram criados visando a tornar-se uma referência para a elaboração dos currículos escolares com o intuito "difundir os princípios da reforma curricular e orientar os professores na busca de novas abordagens e metodologias. Eles traçam um novo perfil para o currículo, apoiado em competências básicas para a inserção dos jovens na vida adulta". Disponível em: $<$ http://portal.inep.gov.br/web/saeb/parametros-curriculares-nacionais $>$. Acesso em: 23 set. 2015.

4 Utilizamos, neste texto, o termo tendências no ensino da matemática e não tendências em Educação Matemática, porque acreditamos que não se pode dar conta das tendências em Educação Matemática somente analisando os livros didáticos, visto que a Educação Matemática está comprometida, também, com outras questões. 
atividades das pessoas; o uso de jogos, que representam um caminho para o fazer matemática em sala de aula, favorecendo a criatividade na elaboração de estratégias e o trabalho em grupo. Ainda tratando das tendências no ensino da matemática, os PCN apontam para o trabalho com temas transversais, que além de envolverem a interdisciplinaridade, contemplam questões de ética, meio ambiente, saúde, pluralidade cultural e orientação sexual (BRASIL, 1998).

Em face às críticas ao livro didático de matemática e considerando que este material vem sendo reestruturado a partir da implementação do ensino fundamental de nove anos e das orientações sugeridas nos $\mathrm{PCN}$, sobretudo no que diz respeito às tendências no ensino da matemática, emerge o interesse por esta temática. Assim, conduzimos uma pesquisa com o objetivo de identificar quais e analisar como as principais tendências no ensino da matemática, sugeridas pelos Parâmetros Curriculares Nacionais, são abordadas nos livros didáticos de matemática, elaborados após implementação do ensino fundamental de nove anos.

\section{Opções metodológicas da investigação}

A pesquisa realizada seguiu uma abordagem qualitativa, na perspectiva da análise de conteúdo (BARDIN, 2014), e consistiu na análise da coleção Praticando Matemática, editada após a implementação do ensino fundamental de nove anos. Focamos esta coleção por ser a coleção com o maior número de exemplares distribuídos pelo PNLD 2014, o último à época em que realizamos a investigação (meados de 2016). Optamos por analisar os quatro livros da coleção dos anos finais porque nos interessava contemplar os dois ciclos finais do ensino fundamental ( $3 .^{\circ}$ e $4 .^{\circ}$ ciclos), que compreendem o fechamento desta etapa escolar.

Ao examinar a coleção, na etapa de interação com os dados (descrição analítica), selecionamos aspectos nos livros que sugeriam a abordagem de alguma das tendências no ensino da matemática, constituindo as unidades de registro (UR). Tais unidades foram organizadas em quadros, nos quais registramos as situações matemáticas em que foram apresentadas. Por último, realizamos as convergências entre as UR, convergindo para unidades temáticas (UT) e, por fim, para as categorias de análise (CA).

Para identificar os conteúdos curriculares que embasam a abordagem das tendências, registramos o título do capítulo do livro em que a abordagem foi apresentada. Por último buscamos situar o "lugar" (introdução de conteúdo, desenvolvimento, atividades/exercícios, notas de rodapé, conclusão de capítulo), na estrutura dos capítulos dos livros, em que as tendências foram evidenciadas. 
E, portanto, mediante a análise que realizamos foram evidenciadas três perspectivas, segundo as quais as tendências no ensino da matemática têm sido desenvolvidas nesta coleção. São elas: abordagem histórica para apresentação e/ou desenvolvimento de conteúdos matemáticos; situações matemáticas como contexto para o desenvolvimento de conteúdos matemáticos e; situações investigativas como cenário de aprendizagem da matemática.

\section{Livros didáticos e as mudanças sociais e educacionais no Brasil: algumas implicações para o ensino da matemática}

A sociedade contemporânea vivencia avanços tecnológicos que trazem implicações ao cenário educacional, na medida em que recursos diversos são inseridos no contexto escolar, tais como computadores, equipamentos de mídia, lousa interativa, materiais manipuláveis diversos, materiais de apoio escolar, etc. Contudo, embora estas possibilidades, o livro didático é considerado, ainda, o principal recurso utilizado em muitas escolas (OLIVEIRA, 2007).

Além disso, as mudanças educacionais no Brasil, tais como a recente reestruturação do ensino fundamental, embora impõem novas exigências à elaboração dos livros didáticos, não minimizam o papel de destaque destes recursos em sala de aula. E, assim, devido à centralidade assumida pelo livro didático nos processos educacionais escolares, conforme Lima (2012), este recurso tem assumido a função de organizador pedagógico em sala de aula, de modo que marca o percurso escolar dos alunos e permanece na sua memória na idade adulta.

O livro didático constitui a principal fonte de informação impressa utilizada por professores e alunos da educação básica, em especial para aqueles que têm acesso restrito aos bens econômicos e culturais. Dessa forma, o livro didático tem assumido lugar de destaque no processo de escolarização no país, carregando, por isso, um alto valor social (LIMA, 2012).

Além disto, face ao modo como é concebido, o livro didático, segundo Lima (2012), pode ser entendido como um documento histórico, que se constitui no contexto das relações socioculturais que se situam na escola e fora dela, ao mesmo tempo que é instituinte destas relações, de modo que esta visão legitima o modo como é entendido, sua abrangência e impactos. Da mesma forma, faz parte da cultura e da memória das gerações, permeando as transformações da sociedade, distinguindo-se por sua função na mediação dos processos educacionais (LIMA, 2012). 
No que diz respeito ao livro didático de matemática, de acordo com D'Ambrosio (2008), a primeira obra escrita no Brasil, de autoria de José Fernandez Pinto Alpoim ${ }^{5}$ e intitulada "Exame de Artilheiro", foi publicada em 1744. A obra foi organizada no intuito de assegurar a ordem social do Brasil-Colônia (1500-1822), pois os livros vindos da Europa não estavam sendo considerados adequados à realidade social e cultural em que o país encontravase à época. Cabe destacar que, embora tenha sido escrita no Brasil, a obra foi impressa na Europa, porque no Brasil não havia, ainda, imprensa, equipamento este que foi trazido somente em 1808 com a chegada da família real.

Ao examinar a relação histórica entre o uso de livros didáticos e o ensino da matemática, Valente (2008) considera que a matemática é, possivelmente, a disciplina escolar que apresenta maior dependência deste material. Acrescenta que

[...] talvez seja possível dizer que a matemática se constitua na disciplina que mais tem a sua trajetória atrelada aos livros didáticos. Das origens de seu ensino como saber técnico-militar, passando por sua ascendência a saber de cultura geral escolar, a trajetória histórica de constituição e desenvolvimento da matemática escolar no Brasil pode ser lida nos livros didáticos (VALENTE, 2008, p. 141).

No que diz respeito à presença histórica do livro didático no ensino, Bittencourt (2004) destaca que a partir de meados do século XIX tornou-se evidente que o livro didático não poderia ser exclusivo do professor, pelo contrário precisava ser acessível ao aluno. Assim,

Esse período correspondeu a uma sensível mudança quanto ao público do livro didático. $\mathrm{O}$ livro didático traz, desde sua origem, uma ambiguidade no que se refere ao seu público. O professor é figura central, mas existe o aluno. O livro didático não pode separá-los (BITTENCOURT, 2004, p. 483).

No período após a proclamação da república, segundo Evangelista (2014), havia preocupação com a reestruturação do material didático de matemática, de modo a incluir novos temas. Neste cenário surgiram duas tendências de elaboração dos livros didáticos: a primeira, consistia em escrever textos, não para o aluno, nem para o professor, mas para o contexto intelectual dos autores; na outra tendência os livros didáticos eram produzidos para os alunos.

Relativamente à forma de utilização escolar dos livros didáticos, Lajolo (1996, p. 4 apud Vorpaguel, 2008, p. 27) considera que em países como o Brasil, este material assume importância em virtude de que

[...] uma precaríssima situação educacional faz com que ele acabe determinando conteúdos e condicionando estratégias de ensino, marcando, pois, de forma decisiva, o que se ensina e como se ensina o que se ensina. Como sugere o adjetivo didático,

$5 \quad$ Militar português com grande experiência em docência. 
que qualifica e define um certo tipo de obra, o livro didático é instrumento específico e importantíssimo de ensino e de aprendizagem formal. Muito embora não seja o único material de que professores e alunos vão valer-se no processo de ensino e aprendizagem, ele pode ser decisivo para a qualidade do aprendizado resultante das atividades escolares.

Este aspecto sinaliza que o cenário educacional no Brasil acaba por legitimar a importância e, talvez, indispensabilidade deste recurso ao assumi-lo como elemento que tem guiado o ensino, haja vista as dimensões do papel que tem assumido. Ressaltamos, entretanto, que o livro didático, em sua função primordial, constitui-se apenas em uma sugestão de abordagem pedagógica para os processos de ensino e aprendizagem na escola, podendo ser compreendido como um interlocutor no diálogo entre professor, aluno e conhecimento.

Destacamos, ainda, que o livro didático não foi ator principal nas questões educacionais que renderam manifestações, discussões e conflitos. Sua trajetória, desde a criação do Instituto Nacional do Livro (1937) até o PNLD (1985), no entanto, é reflexo de visões e ações políticas e econômicas, que permearam o cenário educacional.

O destaque ao livro didático ocorreu, inicialmente, na década de 1930, quando o governo federal à época, preocupado com a segurança nacional, criou comissões para analisar os livros, regulamentando, também, as condições de produção, importação e utilização escolar destes recursos. Este fato evidencia que houve, àquela altura, influência política em relação à utilização do livro didático. Nota-se, também, por meio das estruturas e dos programas criados até que se chegasse ao PNLD, que houve preocupação do poder público com a fiscalização e controle das ações educativas, característica marcante dos governos ditatoriais.

No que diz respeito à influência econômica para a difusão do livro didático no Brasil, a partir da segunda metade do século XX houve incentivo do governo federal por meio dos acordos MEC-USAID ${ }^{6}$ para a produção e edição de livros didáticos. Neste sentido, o contexto educacional brasileiro colaborou para a expansão do mercado editorial à medida que o modelo educacional tecnicista, profissionalizante, com vistas à formação de mão de obra para a indústria, trouxe um novo formato para os livros didáticos. Estes passaram a disponibilizar espaços para uso dos alunos (preencher, assinalar, responder atividades), promovendo a individualização do uso, o que inviabilizou a sua reutilização. Este aspecto favoreceu o setor econômico, que alcançou lucro significativo com a comercialização de livros didáticos para todo o sistema de ensino.

6 Acordos realizados entre o Ministério da Educação do Brasil e a United States Agency for International Development, nos anos de 1960, com o objetivo de promover mudanças na educação brasileira. 
Na década de 1970 houve preocupação tanto em relação ao mercado editorial, que devido à expansão impôs a necessidade de regularização dos preços, quanto no que diz respeito ao custo do livro para aquisição pelas famílias. Com isso foram criadas ações assistenciais do governo para distribuição de livros didáticos a alunos de famílias de baixo poder aquisitivo. Na década seguinte, 1980, o poder público assumiu integralmente a responsabilidade pela política educacional do livro didático no Brasil que, com algumas alterações, tem sido mantida até hoje, custeando a sua produção e distribuição às escolas em todo país.

Por fim, ao olhar para o cenário educacional no Brasil, desde as primeiras iniciativas de elaboração de livros didáticos até a sua ampla disseminação, verifica-se que este movimento é permeado por questões de cunho político, econômico e social, em face as quais foram propiciadas as condições à constituição e efetivação desta política, concretizada pelo PNLD, que representa um importante avanço para a educação nacional.

\section{Tendências no ensino de matemática e a redefinição de livros didáticos}

A matemática, que se originou no contexto das práticas cotidianas das pessoas associadas às necessidades básicas, tais como medir, contar, representar e realizar construções, consolidou-se e expandiu-se em várias civilizações. Em face a esta expansão, a matemática acabou contribuindo para a evolução cultural e social da humanidade. Pelas suas especificidades, pelo modo como estrutura-se e permeia as atividades sociais das pessoas, a matemática é vista de diferentes maneiras por aqueles que com ela se envolvem, porém, de maneira geral, tem sido admitida como a ciência dos números e das formas, das relações e das medidas, das inferências, levando-se em conta que suas características apontam para precisão, rigor e exatidão (EVANGELISTA, 2014).

Além disso, o ensino da matemática na escola tem sido permeado por diversas modificações, aspecto este que tem solicitado reformulações nos materiais escolares em diferentes momentos. Dentre as principais mudanças destaca-se aquela concretizada na década de 1970 e início dos anos de 1980, mediante a qual houve uma renovação nas propostas curriculares da matemática. Para Evangelista (2014), esta reformulação foi marcada pela preocupação de privilegiar a abordagem histórica de conteúdos e temas da matemática, ênfase na importância da geometria e a compreensão de conceitos.

Posterior a esta, destacaram-se propostas curriculares de matemática que evidenciavam a necessidade de incorporação das tecnologias da informação e comunicação, 
dos jogos e materiais concretos, da modelagem matemática, etc., nos processos educativos como uma forma de tornar a aprendizagem da matemática significativa para o aluno.

A partir deste cenário para o ensino da matemática deu-se início a constituição de algumas tendências (relativas ao ensino da matemática), que passam a ser consideradas alternativas para as abordagens de sala de aula, conforme sugerem os Parâmetros Curriculares Nacionais. E, por conseguinte, a consolidação das tendências para o ensino da matemática, seguida da publicação dos $\mathrm{PCN}$, implicaram em mudanças na elaboração de materiais didáticos, especialmente os livros didáticos. Sobre isto, Oliveira (2007) considera que os autores de livros didáticos passaram a orientar-se pelos PCN e que as propostas de livros de matemática têm refletido as orientações dos mesmos. Acrescenta que os livros passaram a ser organizados em blocos de conteúdos, contemplando Aritmética ${ }^{7}$, Geometria $^{8}$, Grandezas e Medidas e Tratamento da Informação, macrocampos estes estabelecidos pelo Ministério da Educação.

Outro aspecto observado nos livros didáticos de matemática, elaborados após a publicação dos PCN, refere-se a uma preocupação em estabelecer conexões com temas trabalho e consumo, saúde e meio ambiente, além de abordar as tendências resolução de problemas, história da matemática, etnomatemática, tecnologias da comunicação, jogos, contextualização e interdisciplinaridade (OLIVEIRA, 2007).

Considerando, portanto, a abordagem de algumas tendências no ensino da matemática nos livros didáticos, apresentamos entendimentos relativos às tendências referenciadas nos Parâmetros Curriculares Nacionais - ensino fundamental, com vistas a explicitar os entendimentos subjacentes ao nosso estudo. As tendências abordadas, são: resolução de problemas; história da matemática; matemática e tecnologias; contextualização e interdisciplinaridade; jogos e materiais didáticos; etnomatemática e; pedagogia de projetos, que não é mencionada nos PCN, mas foi identificada na coleção analisada.

Esclarecemos, ainda, que em nossas análises não nos preocupamos em definir as tendências no ensino de matemática, delimitando-as como metodologias ou estratégias de ensino ou como abordagem didática, porque entendemos que se assim o fizéssemos estaríamos restringindo o olhar sobre as situações matemáticas que poderiam evidenciar a abordagem de uma ou outra tendência no ensino da matemática.

\section{Resolução de Problemas}

8 Os PCN de $1998,3^{\circ}$ e $4^{\circ}$ ciclo, abordam como Espaço e Forma. 
A resolução de problemas é uma tendência no ensino da matemática que surgiu associada à ideia de problema. Para Romanatto (2012), um problema é uma situação que demanda um conjunto de atividades para se chegar a um resultado, o qual não se mostra $a$ priori, mas tem de ser construído. Assumindo uma perspectiva de desafio, de construção de conceitos, Onuchic (1999, p. 25) argumenta que

[...] o ponto de partida das atividades matemáticas não é a definição, mas o problema; que o problema não é um exercício no qual o aluno aplica, de forma quase mecânica, uma fórmula ou uma determinada técnica operatória; que aproximações sucessivas ao conceito criado são construídas para resolver um certo tipo de problema e que, num outro momento, o aluno utiliza o que já aprendeu para resolver outros problemas; que o aluno não constrói um conceito em resposta a um problema, mas constrói um campo de conceitos que tomam sentido num campo de problemas; que a Resolução de Problemas não é uma atividade para ser desenvolvida em paralelo ou como aplicação da aprendizagem, mas como orientação para a aprendizagem.

A resolução de problemas, contudo, consolidou-se no início do século XX com o trabalho de George Pólya ${ }^{9}$, intitulado How to solve it, no qual discutia o ensino de matemática por meio da resolução de problemas, estruturando-a em quatro fases:

[...] primeiro, temos de compreender o problema, temos de perceber claramente o que é necessário. Segundo, temos de ver como os diversos itens estão interrelacionados, como a incógnita está ligada aos dados, para termos a ideia da resolução, para estabelecermos um plano. Terceiro, executamos o nosso plano. Quarto, fazemos um retrospecto da resolução completa, revendo-a e discutindo-a (POLYA, 1978, p. 3-4).

De acordo com Stanic e Kilpatrick (1989) a resolução de problemas, na perspectiva de Pólya, consiste em uma arte prática, como nadar ou tocar piano, que são aprendidas tanto por imitação quanto por prática. Para Pólya, embora os problemas rotineiros pudessem cumprir certas funções pedagógicas, só por meio de problemas não rotineiros os alunos poderiam desenvolver a capacidade de resolver problemas (STANIC; KILPATRICK, 1989).

\section{História da Matemática}

A abordagem da história da matemática no ensino escolar surgiu ainda na década de 1970, a partir da preocupação em promover a abordagem histórica dos conteúdos nos materiais didáticos. Além disso, considerando a constituição histórica e processual da matemática, em que conceitos e propriedades são consolidados e utilizados nas práticas sociais e profissionais das pessoas em diferentes períodos históricos, Miguel e Miorim (2004, p.53) consideram que a história da matemática pode levar o aluno a perceber

9 Matemático Húngaro, nascido em 1887, dedicou-se especialmente à arte de resolução de problemas de matemática. Disponível em: <http://cmup.fc.up.pt/cmup/polya/polya_introducao2.html>. Acesso em: 6 ago. 2015 . 
(1) a matemática como uma criação humana; (2) as razões pelas quais as pessoas fazem matemática; (3) as necessidades práticas, sociais, econômicas e físicas que servem de estímulo ao desenvolvimento das ideias matemáticas; (4) as conexões existentes entre matemática e religião, matemática e lógica, etc.; (5) a curiosidade estritamente intelectual que pode levar à generalização e extensão de ideias e teorias; (6) as percepções que os matemáticos têm do próprio objeto da matemática, as quais mudam e se desenvolvem ao longo do tempo; (7) a natureza de uma estrutura, de uma axiomatização e de uma prova.

A partir desta compreensão, Miguel e Miorim (2004) consideram que a história da matemática pode constituir-se um ponto de referência para a problematização pedagógica e para a transformação qualitativa do ensino da matemática. De maneira similar, Beatriz D’Ambrosio afirma que a história da matemática serve para todos, alunos, professores, pais e público em geral e tem como algumas de suas finalidades,

1) situar a matemática como uma manifestação cultural de todos os povos em todos os tempos, como a linguagem, os costumes, os valores, as crenças e os hábitos, e como tal diversificada nas suas origens e na sua evolução; 2) mostrar que a matemática que se estuda nas escolas é uma das formas de Matemática desenvolvidas pela humanidade; 3 ) destacar que essa Matemática teve sua origem nas culturas da Antiguidade mediterrânea e se desenvolveu ao longo da Idade Média e somente a partir do século XVII se organizou como um corpo de conhecimentos, como um estilo próprio; e desde então foi incorporada aos sistemas escolares das nações colonizadoras e se tornou indispensável em todo o mundo em consequência do desenvolvimento científico, tecnológico e econômico (D’AMBROSIO, 2005, p. 223).

Assim, D’Ambrosio (2005) esclarece que conhecer a matemática de ontem é uma forma de orientar o aprendizado da matemática de hoje, pois permite a ressignificação, por parte do aluno em face às suas experiências, do saber matemático produzido pela sociedade ao colocá-lo em contato com informações de diferentes épocas e culturas, com linguagens matemáticas geralmente não manifestadas na matemática escolar.

\section{Tecnologias no ensino da Matemática}

No Brasil a inserção das tecnologias no ensino da matemática, especialmente as tecnologias de informação e comunicação, despontou no início dos anos 1980, motivado pela disseminação das tecnologias e sua influência nas atividades das pessoas. Neste sentido, Borba e Penteado (2001) sugerem que a relação entre tecnologias e Educação Matemática precisa ser pensada como uma transformação da prática educativa. Entendem que as tecnologias abrem possibilidades de mudanças dentro do próprio conhecimento, pois “é possível haver ressonância entre uma dada pedagogia, uma mídia e uma visão de conhecimento" (IBIDEM, p.43).

Acrescentam que o uso das tecnologias na prática pedagógica pode estimular a utilização de problemas abertos, de formulação de conjecturas em que a sistematização atinge o ápice de um processo de investigação e não de exercícios de resolução procedimental, 
subsidiados por uma mídia (BORBA; PENTEADO, 2001). A prática realizada nesta perspectiva alcança a construção do conhecimento como processo e não como produto.

Tendo em vista as possibilidades advindas das tecnologias no ensino da matemática, consideramos que a partir dos processos viabilizados por estes recursos, os alunos têm a oportunidade de apropriar-se destes elementos e modificar suas ações relacionadas à aprendizagem. Ressaltamos, contudo, que o uso das tecnologias, principalmente na escola, deve ser crítico e consciente, caso contrário corre-se o risco de torná-lo meramente ilustrativo e desinteressante, desvinculado dos processos de ensino e aprendizagem.

\section{Contextualização e Interdisciplinaridade}

A contextualização e a interdisciplinaridade constituem-se em tendências recentes em Educação Matemática, as quais vêm sendo incorporadas às propostas pedagógicas da educação básica. No que se refere à contextualização, Tomaz e David (2008) pontuam que o ensino precisa estar articulado às práticas e necessidades sociais, porém isso não significa que todo conhecimento a ser aprendido deva partir das situações reais do aluno. Acrescentam que outra maneira de trabalhar a contextualização é por meio de relações com outras disciplinas, o que pode ser entendido como interdisciplinaridade.

Além disso, pontuam que "a interdisciplinaridade poderia ser alcançada quando os conhecimentos de várias disciplinas são utilizados para resolver um problema ou compreender um determinado fenômeno, sob diferentes pontos de vista" (TOMAZ; DAVID, 2008, p. 16).

Assim, desenvolver práticas matemáticas contextualizadas pode promover uma relação positiva em termos do desenvolvimento do conhecimento matemático pelo aluno, pois é uma forma de oportunizá-lo a abordar a matemática em diferentes situações. Esta abordagem, por sua vez, pode auxiliar a compreensão crítica e responsável da sociedade, com possibilidade de uma formação integral do aluno, pois articulam diferentes áreas do conhecimento.

\section{Jogos e materiais didáticos}

Mediante a exigência da sociedade por uma escola de qualidade, pesquisadores e especialistas têm apresentado propostas de mudança para o contexto escolar no sentido de buscar formas diferentes de ensinar, propiciando o desenvolvimento de práticas que promovam a aprendizagem em um processo de interação e investigação. Foi nesta perspectiva, e visando promover a aprendizagem de forma menos expositiva e impositiva, que consolidaram-se as atividades educativas envolvendo jogos e materiais didáticos no ensino da matemática. 
Ao buscar caracterizar jogos educativos, Kamii e De Vries (1991, p. 9 apud Grando 1995, p. 128) dizem que "um bom jogo não é aquele que necessariamente a criança pode dominar corretamente. O importante é que a criança possa jogar de uma maneira lógica e desafiadora para si mesma e para seu grupo”. Referenciando Oldfield (1991), Grando (1995, p. 128) acrescentam que

[...] o jogo matemático é uma atividade que envolve desafio contra uma tarefa ou adversários, enfrentada individual ou coletivamente, uma atividade governada por um conjunto de regras que representam a estrutura fundamental de jogo, uma atividade que tem começo/meio e fim e, finalmente, uma atividade que possui objetivos cognitivos matemáticos.

No que diz respeito ao potencial dos jogos nos processos educativos, Grando (1995) afirma que estes recursos se mostram produtivos para o professor, pois podem favorecer a aprendizagem do aluno a medida que estimulam a capacidade de pensar, levantar hipóteses e testá-las, refletir, analisar, além de propiciar autonomia e socialização.

No entanto, ao utilizar algum material didático ou um jogo como alternativa de ensino o professor precisa considerar sua adequação ao conteúdo a ser desenvolvido, para que de fato possa auxiliar no processo, considerando que nenhum material é válido por si só e que nem sempre o material visualmente mais atrativo é o mais adequado.

\section{Etnomatemática}

Atualmente, segundo D’Ambrosio (2002), a etnomatemática é considerada uma subárea da história da matemática, ao mesmo tempo que possui uma relação natural com a antropologia e as ciências da cognição. Possui, ainda, uma dimensão política e ética que focaliza o resgate da dignidade cultural do ser humano, que por vezes é negada pela discriminação e exclusão social, praticada em diversos espaços, entre eles no ambiente escolar onde predominam abordagens clássicas (de caráter expositivo) da matemática.

D’Ambrosio (2002) refere-se à etnomatemática como sendo a matemática praticada por grupos culturais, tais como grupos de trabalhadores, comunidades urbanas e rurais, sociedades indígenas, classes profissionais, crianças de uma certa faixa etária e também por outros grupos que se identificam por objetivos e tradições comuns. Tal processo enfatiza a dinâmica do saber/fazer matemático das diferentes culturas, ao tempo que reconhece que os indivíduos de um grupo compartilham seus conhecimentos, linguagem, sistemas de explicação, culinária, costumes e valores, aspectos estes que os fazem pertencer a uma cultura.

Conforme afirma D’Ambrosio (2002, p. 46), a proposta pedagógica da etnomatemática "é fazer da matemática algo vivo, lidando com situações reais no tempo e no 
espaço [...]”, reconhecendo na educação, efetivamente, a importância das várias culturas e tradições na "[...] formação de uma nova civilização, transcultural e transdisciplinar". Nesta perspectiva, há reconhecimento de que as matemáticas praticadas ao longo da história variam de acordo com o lugar geográfico, cultura, economia e outros aspectos que propiciam diferentes manifestações dessas práticas. E respeitá-las e compreendê-las é função da escola e da matemática.

\section{Pedagogia de Projetos}

A pedagogia de projetos, segundo Boutinet (2002 apud Malheiros, 2007), visa, entre outras coisas, conceder ao aluno o protagonismo nos processos de ensino e aprendizagem por meio de ações que não dissociam teoria e prática. Esta abordagem pode assumir distintas funções nas práticas educativas, porém Hernández e Ventura (1998, p.61) citam o propósito de

[...] favorecer a criação de estratégias de organização dos conhecimentos escolares em relação a: 1) o tratamento da informação, e 2) a relação entre os diferentes conteúdos em torno de problemas ou hipóteses que facilitem aos alunos a construção de seus conhecimentos, a transformação da informação procedente dos diferentes saberes disciplinares em conhecimento próprio.

Assim, segundo Malheiros (2007), para a consolidação dos objetivos da pedagogia de projetos, o professor precisa promover a negociação pedagógica (decisão sobre o tema), de modo que o projeto venha a ser interessante aos alunos, caso contrário, o projeto é do professor, da escola, mas não dos alunos.

Ao destacar a importância da participação ativa dos alunos, bem como o papel do professor no trabalho com projetos, Prado (2005, p.13) compreende que

[...] na pedagogia de projetos, o aluno aprende no processo de produzir, levantar dúvidas, pesquisar e criar relações que incentivam novas buscas, descobertas, compreensões e reconstruções de conhecimento. Portanto, o papel do professor deixa de ser aquele que ensina por meio da transmissão de informações - que tem como centro do processo a atuação do professor - para criar situações de aprendizagem cujo foco incida sobre as relações que se estabelecem nesse processo, cabendo ao professor realizar as mediações necessárias para que o aluno possa encontrar sentido naquilo que está aprendendo a partir das relações criadas nessas situações.

Em outras palavras, o trabalho com projetos é considerado uma abordagem investigativa (MALHEIROS, 2007). Compreendemos, portanto, que no ensino pautado na investigação, o aluno é chamado a agir e seu envolvimento ativo é condição fundamental à aprendizagem, pois ele aprende quando mobiliza os recursos cognitivos e afetivos para atingir um objetivo. 


\section{Perspectivas de abordagem das tendências no ensino da matemática na coleção "Praticando Matemática"}

Ao analisarmos os livros da coleção Praticando Matemática identificamos 158 situações matemáticas, que caracterizam a abordagem de alguma das tendências no ensino da matemática. Estas situações, que denominamos unidades de registro (UR), foram reduzidas, pela proximidade da abordagem a que se referiam, a dez unidades temáticas (UT), as quais foram novamente agrupadas, culminando nas três categorias de análise (CA) aqui discutidas: abordagem histórica para a apresentação e/ou desenvolvimento de conteúdos matemáticos $\left(\mathrm{CA}_{1}\right)$; situações matemáticas como contexto para o desenvolvimento de conteúdos matemáticos $\left(\mathrm{CA}_{2}\right)$ e; situações investigativas como cenário de aprendizagem da matemática $\left(\mathrm{CA}_{3}\right)$. $\mathrm{O}$ quadro a seguir indica a organização e redução das unidades de registro identificadas.

\begin{tabular}{|c|c|c|}
\hline Unidades de Registro (UR) & UT & CA \\
\hline UR: $99,120,136,138,139,141,152,153$ & $\mathrm{UT}_{1}$ & \multirow{3}{*}{ CA } \\
\hline UR: $10,15,56,76,101$ & $\mathrm{UT}_{6}$ & \\
\hline $\begin{array}{l}\text { UR: } 1,3,4,5,16,30,32,36,37,38,55,58,64,68,77,88,93,94,100 \\
104,105,112,113,114,129,133,137,149,158 .\end{array}$ & $\mathrm{UR}_{10}$ & \\
\hline UR: $8,9,61,62,70,78,102,107,111$ & $\mathrm{UT}_{2}$ & \multirow{6}{*}{ CA } \\
\hline UR: $17,18,20,27,43,63,67,106,144,156$ & $\mathrm{UT}_{3}$ & \\
\hline UR: $7,26,34,49,50,51,52,96,97$ & $\mathrm{UT}_{4}$ & \\
\hline UR: $22,31,35,45,75,89,90,92,121,123,124,125,145,155$ & $\mathrm{UT}_{7}$ & \\
\hline $\begin{array}{l}\text { UR: } 11,12,19,21,23,24,39,41,42,44,47,48,57,59,60,65,66,69 \\
71,72,73,74,79,80,81,82,83,86,95,103,108,115,117,118,119 \\
130,132,134,135,140,146,148,154,157\end{array}$ & $\mathrm{UT}_{8}$ & \\
\hline $\begin{array}{l}\text { UR: } 2,6,13,29,33,40,46,53,54,91,98,109,110,122,126,127 \\
128,142,143,145,147,151 .\end{array}$ & $\mathrm{UT}_{9}$ & \\
\hline UR: $14,25,28,84,85,87,116,150$ & $\mathrm{UT}_{5}$ & $\mathrm{CA}_{3}$ \\
\hline
\end{tabular}

\section{Abordagem histórica à apresentação e/ou desenvolvimento de conteúdos matemáticos}

Os quatro livros da coleção Praticando Matemática apresentam situações matemáticas de caráter eminentemente histórico, as quais contemplam o desenvolvimento da matemática e a apresentação de nomes de matemáticos notáveis. Uma característica importante da coleção é a apresentação de resumos biográficos de matemáticos como informação adicional ( $\left.\mathrm{UT}_{1}\right)$, que são pequenas biografias, evidenciadas nas $\mathrm{UR}_{99}, \mathrm{UR}_{120}, \mathrm{UR}_{136}$ e $\mathrm{UR}_{141}$, apresentadas a seguir.

$\mathrm{UR}_{99}$ - Carl Friedrich Gauss foi um matemático alemão que viveu de 1777 a 1855. Já adulto divertia-se ao declarar que aprendeu a contar antes mesmo de saber falar. Por seus muitos trabalhos em vários ramos da matemática, é considerado hoje um dos maiores matemáticos de todos os tempos. ( $7^{\circ}$ ano, p. 10).

$\mathrm{UR}_{120}$ - Euclides foi um dos maiores matemáticos gregos da antiguidade. [...]. Euclides nos deixou um conjunto de livros de matemática, os Elementos, que pode ser considerado um dos mais importantes textos da história da matemática. [...]. Por esses motivos, Euclides é considerado o "Pai da Geometria" e o fundador do chamado "Método Axiomático da Matemática". [...]. (7. ${ }^{\circ}$ ano, p. 172). 
$\mathrm{UR}_{136}$ - Um francês, nascido em 1540, teve grande importância no desenvolvimento da Álgebra. François Viète era advogado, mas dedicava seu tempo livre à matemática. Em seu livro In Arten Analyticam Isagoge, publicado em 1591, mostrou a vantagem de representar um número desconhecido (que chamamos de incógnita) por uma letra. (7. ${ }^{\circ}$ ano, p. 49)

$\mathrm{UR}_{141}$ - René Descartes du Perron e o sistema cartesiano. [...]. Além da matemática, Descartes dedicou-se também à Filosofia e à Física.[...]. Na matemática, trouxe contribuições importantes e desenvolveu o campo que hoje conhecemos como Geometria Analítica. (7. ${ }^{\circ}$ ano, p. 86)

$\mathrm{Na}$ maioria das vezes em que estas situações são apresentadas na coleção, elas estão presentes no Desenvolvimento do conteúdo. Por exemplo, quando o conteúdo proposto se refere à álgebra, a mini biografia traz informações sobre matemáticos associados ao desenvolvimento desta subárea da matemática $\left(\mathrm{UR}_{136}\right)$. Em alguns casos as minibiografias aparecem como encerramento de capítulo, o que, embora as mantenha conectadas ao conteúdo abordado, consistem em uma informação adicional, que não deveria ser a finalidade da abordagem histórica proposta nos livros didáticos escolares.

Outra forma de abordagem histórica identificada consiste na abordagem histórica como contexto para realização de operações matemáticas fundamentais ( $\left.\mathrm{UT}_{6}\right)$. Por vezes, consistem na utilização de dados históricos para a realização de operações de adição e subtração $\left(\mathrm{UR}_{15}\right)$ e outras operações matemáticas fundamentais $\left(\mathrm{UR}_{10}, \mathrm{UR}_{56}, \mathrm{UR}_{75}, \mathrm{UR}_{76} \mathrm{e}\right.$ $\left.\mathrm{UR}_{101}\right)$. São apresentadas, principalmente, nas seções de Exercícios, Revisando e Autoavaliação, sempre conectadas ao conteúdo matemático abordado, mas, servindo fundamentalmente para fornecer elementos para realização de operações matemáticas.

$\mathrm{UR}_{10}-\mathrm{O}$ primeiro censo brasileiro foi realizado em 1872. Na época, o Brasil era uma monarquia e ainda existia escravidão. Foram contadas 9930480 pessoas das quais 1510806 foram declaradas escravas. Em 1872, quantas pessoas foram declaradas não escravas no Brasil? (6. ${ }^{\circ}$ ano, p. 45)

$\mathrm{UR}_{56}$ - Significado do código de barras: Situação de aplicação dos números naturais na criação de códigos de barras. (7. ${ }^{\circ}$ ano, p.19)

$\mathrm{UR}_{75}$ - Os conhecimentos matemáticos são utilizados em outras ciências e em inúmeras atividades humanas. Razões e Geografia (número de habitantes/área $\mathrm{em} \mathrm{km}^{2}$; Razões e Física (velocidade= tempo/distância). (7. ${ }^{\circ}$ ano, p. 108).

$\mathrm{UR}_{76}$ - A densidade de um corpo é o quociente entre a sua massa e o seu volume, e um corpo pode boiar na água se tem densidade menor que $1 \mathrm{~g} / \mathrm{cm}^{3}$. Sejam três corpos [...]. Desses corpos podem flutuar na água? (7. ano, p. 113).

$\mathrm{UR}_{101}$ - O sistema de numeração que usamos é de base dez. Os computadores utilizam o sistema binário, ou seja, de base dois. [...]. (8. ${ }^{\circ}$ ano, p. 42).

$\mathrm{Na} \mathrm{UT}_{10}$, a qual circunscreve as situações mencionadas nas $\mathrm{UR}_{38}, \mathrm{UR}_{94}, \mathrm{UR}_{114} \mathrm{e}$ $\mathrm{UR}_{158}$, são abordadas as principais situações referentes à etnomatemática, a qual está, de maneira geral, bastante restrita às civilizações antigas egípcia, romana, grega.

$\mathrm{UR}_{38}$ - Os numerais decimais não tiveram um único “inventor”. Muitos matemáticos contribuíram para sua criação e aperfeiçoamento. Conheça alguns deles: François Viète (1540-1603) [...]. Simon Stevin (15481620) [...]. G. A. Magini (1555-1617) [...]. (6. ${ }^{\circ}$ ano, p. 200)

$\mathrm{UR}_{94}$ - Aryabhata, poeta, astrônomo e matemático hindu, nasceu em 476. Aos 23 anos terminou a obra Aryabhatiya, que é um dos mais antigos textos hindus conhecidos sobre Matemática e Astronomia. [...]. 
Aryabhata escrevia usando versos e para resolver problemas de adivinhação com números, costumava usar as operações inversas. [...]. (7. ${ }^{\circ}$ ano, p. 215)

$\mathrm{UR}_{114}$ - A álgebra é um ramo da matemática que trabalha com incógnitas e variáveis. Assim como as demais áreas da matemática, a álgebra não foi criada por uma única pessoa ou sociedade. [...] Atribui-se a Diofante, que viveu em Alexandria, no Egito, por volta do século III d. C., as primeiras tentativas de criar uma notação algébrica. [...]. (8. ${ }^{\circ}$ ano, p. 77$)$.

$\mathrm{UR}_{158}$ - O juro, entendido como uma compensação para quem empresta dinheiro ou bens é mais antigo que a moeda, o dinheiro. Há registros de que os sumérios, por volta de 3000 a. C., tinham um sistema de empréstimo envolvendo grãos (cereais) e também prata. Hamurabi, rei da Babilônia de 1792 a. C. a 1750 a. C., escreveu o mais antigo código de leis que se tem notícia. Artigos desse código tratam de juros. [...]. (9. ${ }^{\circ}$ ano, p. 255).

Ressaltamos, entretanto, que embora tais abordagens poderiam contemplar aspectos da matemática desenvolvida por matemáticos modernos e contemporâneos, a abordagem apresentada é, sem dúvida, muito importante, já que estas civilizações (egípcia, romana e grega) construíram os alicerces da matemática, os quais possibilitaram grandes avanços à própria matemática e, também, das civilizações que a constituíram. Verificamos, ainda, que a coleção não oferece muito espaço às práticas matemáticas de grupos culturais dos tempos contemporâneos, a matemática popular, às práticas não escolares. E mesmo trazendo recortes sobre criações matemáticas, situações matemáticas e matemáticos importantes no desenvolvimento da matemática, verificamos que a abordagem apresentada contempla, parcialmente, as possibilidades da etnomatemática ao ensino da matemática

Em síntese, verificamos que a coleção busca abordar contextos históricos à abordagem de diversos conteúdos matemáticos. E embora nem todas as abordagens históricas tenham propiciado possibilidades claras de aprofundamento da relação história-conteúdo, a maioria cumpre o papel que lhes é atribuído, que é oportunizar ao aluno perceber a matemática como uma criação humana. Ou seja, a abordagem evidenciada na coleção coloca as tendências, algumas vezes, num nível de informação sem propor nada a mais do que o exposto e sem evidenciar que não somente grandes gênios podem fazer matemática.

\section{Situações matemáticas como contexto para o desenvolvimento de conteúdos matemáticos}

Esta categoria constitui-se mediante o agrupamento das situações matemáticas associadas à abordagem das tendências no ensino da matemática que estão voltadas ao desenvolvimento do conteúdo. Algumas situações propõem o uso de tecnologias como recurso para realização de operações matemáticas fundamentais $\left(\mathrm{UT}_{2}\right)$, tais como uso de calculadora para a realização de subtração $\left(\mathrm{UR}_{8}\right)$, potências $\left(\mathrm{UR}_{61}\right)$, cálculo de raiz quadrada $\left(\mathrm{UR}_{62}\right)$, porcentagem $\left(\mathrm{UR}_{78}\right)$, frações $\left(\mathrm{UR}_{102}\right)$ e introdução de algumas funções da calculadora $\left(\mathrm{UR}_{9}\right)$. 
$\mathrm{UR}_{8}$ - Minha calculadora tem lugar para 8 algarismos. Eu digitei nela o maior número possível, do qual subtraí o número de habitantes do estado de São Paulo, obtendo como resultado 63033472. Qual era a população do estado de São Paulo nesse ano? (6. ${ }^{\circ}$ ano, p. 38)

$\mathrm{UR}_{102}$ - Use a calculadora para expressar as frações na forma decimal e indique quais são dízimas periódicas. $\left(8 .^{\circ}\right.$ ano, p. 18)

Contudo, observamos que as atividades sugerem o uso de calculadora apenas para a obtenção do resultado da operação apresentada, ou seja, a calculadora é usada de modo a facilitar a realização da operação matemática. Além disso, não encontramos situações voltadas ao uso de calculadoras ou softwares de forma investigativa, ou que favoreçam discussões sobre o uso destes recursos e sobre formas de inseri-los no desenvolvimento de conteúdos.

Observamos, ainda, a partir da análise deste aspecto na coleção, a ausência de atividades envolvendo outras tecnologias, principalmente computadores. Embora cada livro didático da coleção sugira sites e softwares matemáticos nas páginas finais, acaba negligenciando a utilização do computador e seus recursos no desenvolvimento dos conteúdos matemáticos, ao tempo que não oportuniza ao aluno o contato com situações matemáticas baseadas nestes recursos, que poderiam favorecer os processos de ensino e de aprendizagem.

Além disso, nesta coleção, algumas situações matemáticas são apresentadas em forma de curiosidades como contexto para abordagem de conceitos e operações matemáticas $\left(\mathrm{UT}_{3}\right)$, como é o caso da apresentação de curiosidade sobre instrumentos de medida de tempo (UR $\left.{ }_{17}\right)$, apresentação de curiosidade matemática para realização de divisão $\left(\mathrm{UR}_{27}\right)$, curiosidade sobre informação de utilidade pública $\left(\mathrm{UR}_{43}\right)$ e curiosidade referente à formação de códigos utilizados em documentos $\left(\mathrm{UR}_{106}\right)$.

$\mathrm{UR}_{17}$ - No relógio de sol o deslocamento da sombra pela haste mede a passagem do tempo. O mais antigo relógio de sol existente está exposto no Museu de Berlim. Acredita-se que pertenceu ao faraó Tutmés III, do Egito (1504- 1450 a. C.) $\left(6 .^{\circ}\right.$ ano, p. 67$)$

$\mathrm{UR}_{43}$ - Você sabe para que serve o Censo? Além de servir para contar a população do país, o Censo coleta dados importantes sobre as condições de vida nos municípios, nos estados e regiões. [...] O governo usa essas informações para, por exemplo, investir em escolas, hospitais, rede elétrica, criação de empregos e muitas outras coisas. (6. ${ }^{\circ}$ ano, p. 230$)$

$\mathrm{UR}_{106}$ - A matemática dos códigos. No dia a dia, muitos números - de carteira de identidade, de CPF, de contas bancárias etc. - são utilizados. Geralmente apresentam um dígito de verificação [...]. A finalidade desse dígito adicional é evitar erros na digitação ou no preenchimento de documentos com números. Um dos métodos empregados para gerar o dígito adicional obedece aos seguintes passos [...]. (8. ${ }^{\circ}$ ano, p. 29)

No entanto, a maioria das situações apresentadas têm como objetivo promover um contexto para a realização de algum tipo de operação matemática, evidenciando claramente a ideia de contextualização no ensino da matemática. Por fim, estas situações em que se busca promover a contextualização da matemática pouco avançam em termos da aprendizagem baseada na investigação, reflexão e interdisciplinaridade. 


\section{A $\mathrm{UT}_{8}$ contempla situações de aprendizagem como contexto para realização de}

operações matemáticas fundamentais, a medida que propõe atividades de realização de operações de adição $\left(\mathrm{UR}_{11}, \mathrm{UR}_{95}\right)$, subtração $\left(\mathrm{UR}_{12}\right.$ e $\left.\mathrm{UR}_{71}\right)$, multiplicação $\left(\mathrm{UR}_{21}\right.$ e $\left.\mathrm{UR}_{41}\right)$, divisão $\left(\mathrm{UR}_{74}\right)$, potenciação $\left(\mathrm{UR}_{24} \mathrm{e} \mathrm{UR}_{103}\right)$, radiciação $\left(\mathrm{UR}_{134}\right)$, porcentagem $\left(\mathrm{UR}_{81}\right.$ e $\left.\mathrm{UR}_{135}\right)$, cálculo de medidas de área envolvendo regiões retangulares $\left(\mathrm{UR}_{47}\right)$, cálculo de volume $\left(\mathrm{UR}_{48}\right)$ e aplicação de cálculo algébrico $\left(\mathrm{UR}_{117}\right.$ e $\left.\mathrm{UR}_{118}\right)$.

Operação de adição

$\mathrm{UR}_{11}$ - Tabela com a quantidade de calorias, por 100 gramas, de algumas frutas. [...] quantas calorias têm a salada de frutas que Carla preparou? (6..$^{\circ}$ ano, p. 47$)$

$\mathrm{UR}_{95}$ - De acordo com o Código de Trânsito Brasileiro, um motorista que tiver 20 ou mais pontos negativos em sua $\mathrm{CNH}$ perde o direito de dirigir por um período. A tabela abaixo apresenta os pontos perdidos, de acordo com sua gravidade. [...]. (7. ${ }^{\circ}$ ano, p. 229)

Operação de subtração

UR $_{12}$ - Dom Pedro II, imperador do Brasil, que morreu em 1891, com 66 anos de idade, começou a reinar quando fez 15 anos. Em que ano ele começou a reinar? (6. ${ }^{\circ}$ ano, p. 48$)$

$\mathrm{UR}_{71}$ - Traz uma tabela que apresenta os fusos horários de algumas cidades do mundo, em relação a Brasília, em fevereiro de 2010. (7. ${ }^{\circ}$ ano, p. 83)

Operação de multiplicação

$\mathrm{UR}_{21}$ - Você conhece o sistema de pontuação das multas de trânsito? [...]. Durante o ano de 2008, João recebeu 2 multas graves, 3 multas médias e 1 multa leve. Quantos pontos foram acrescentados a carteira de João, se uma multa média foi cancelada? (6. ${ }^{\circ}$ ano, p. 71$)$

$\mathrm{UR}_{41}$ - A "terra" é uma moeda social criada em Vila Velha, comunidade da Região Metropolitana de Vitória. Essa moeda só circula na comunidade, e um real vale o mesmo que um "terra". Mas quem compra com "terra", compra mais barato. O preço do pãozinho é R $\$ 0,15$, ou 0,10 "terra" [...]. (6. ano, p. 221)

Operação de divisão

$\mathrm{UR}_{74}$ - O menor país do mundo em extensão é o Estado do Vaticano, com área de $400000 \mathrm{~m}^{2}$. Se o território do Vaticano tivesse a forma de um quadrado, então a medida de seus lados estaria entre? (9. ${ }^{\circ}$ ano, p. 40 )

Cálculo de porcentagem

$\mathrm{UR}_{81}-[\ldots]$ Para evitar lesões na coluna vertebral, o peso de uma mochila e do material contido dentro dela não devem ultrapassar $10 \%$ do peso do estudante que a transporta. [...]. (7. ${ }^{\circ}$ ano, p. 126)

$\mathrm{UR}_{135}$ - Existem leis municipais que regulamentam a ocupação dos terrenos, principalmente os reservados a loteamentos e condomínios. Por exemplo, a área construída deverá ocupar no máximo certa porcentagem da área total do terreno. No problema a área construída ocupa que porcentagem da área total do terreno? $\left(9 .^{\circ}\right.$ ano, p. 44)

Cálculo de potências

$\mathrm{UR}_{24}$ - Você sabe o que é e-mail? É uma mensagem enviada ou recebida através do computador. Flávio recebeu por e-mail um desenho engraçado de um monstrinho. Ele abriu o arquivo e, dez segundos depois, viu que em vez de um, havia dois monstrinhos na tela do computador [...]. (6. ${ }^{\circ}$ ano, p. 83)

$\mathrm{UR}_{103}$ - Digite na calculadora: $1,732050808 \mathrm{x}=$ para elevar esse número ao quadrado. (9. ${ }^{\circ}$ ano, p. 20 )

Cálculo de raízes

$\mathrm{UR}_{134}$ - O menor país do mundo em extensão é o Estado do Vaticano, com área de $400000 \mathrm{~m}^{2}$. Se o território do Vaticano tivesse a forma de um quadrado, então a medida de seus lados estaria entre? (9. ${ }^{\circ}$ ano, p. 40)

Cálculo de área e volume

$\mathrm{UR}_{47}$ - As normas de arquitetura recomendam que um quarto de uma moradia tenha, no mínimo, $9 \mathrm{~m}^{2}$. Qual das plantas abaixo representa um quarto que satisfaz a essa norma? ( $6 .^{\circ}$ ano, $\left.\mathrm{p} .246\right)$ 
$\mathrm{UR}_{48}$ - Uma torneira está estragada e, mesmo fechada, pinga. Durante meia hora a torneira perde $2 \mathrm{dm}^{3} \mathrm{de}$ água. Quantos litros de água a torneira perde em 1 dia? Desperdício, não! Desperdiçar água não significa só pagar mais pela conta todo mês. A água é um bem precioso e cada vez mais escasso em nosso planeta.

Precisamos economizá-la se não quisermos que falte no futuro. Pense nisso! (6. ${ }^{\circ}$ ano, p. 254)

Cálculo algébrico

$\mathrm{UR}_{117}$ - A estatura de um adulto do sexo feminino pode ser estimada, através das alturas de seus pais, pela expressão [...]. Segundo a fórmula, se João tem $1,72 \mathrm{~m}$ de altura [...]. (8. ${ }^{\circ}$ ano, p. 100)

$\mathrm{UR}_{118}$ - Cuidando da alimentação. Quando o ser vivo se alimenta, incorpora a energia que possibilita o crescimento, o desenvolvimento e a renovação das células e dos tecidos do organismo. [...]. Por isso é importante tem uma alimentação com variedade de nutrientes. [...]. (8. ${ }^{\circ}$ ano, p. 127)

As situações matemáticas circunscritas na $\mathrm{UT}_{8}$ caracterizam-se por constituírem um contexto para a realização de cálculos matemáticos, compreendendo os blocos de conteúdo, Números e Operações, Espaço e Forma e Tratamento da Informação. Ressaltamos que estas situações matemáticas são apresentadas, principalmente no Desenvolvimento dos conteúdos e nas seções de atividades para resolver, como seção Revisando, Autoavaliação e Exercícios.

Destacamos, também, situações associadas ao uso de jogos e materiais didáticos, tal como uma atividade apresentada no livro do $8 .^{\circ}$ ano, no bloco de conteúdos Números e Operações da Seção livre, que refere-se a um jogo que envolve sistemas de equações.

A última unidade temática compreendida por esta categoria refere-se a situações de aprendizagem para representação, interpretação e aplicação de noções matemáticas ( $\mathrm{UT}_{9}$ ). Nesta unidade é abordada a notação simbólica e representação matemática $\left(\mathrm{UR}_{13}\right)$, leitura de informação tabular e gráfica $\left(\mathrm{UR}_{29}\right)$, identificação de ângulos $\left(\mathrm{UR}_{33}\right)$, representação numérica $\left(\mathrm{UR}_{40}\right)$, apresentação do sistema métrico decimal e de unidades informais $\left(\mathrm{UR}_{46}\right)$, representações de números naturais por meio de gráficos e tabelas $\left(\mathrm{UR}_{53}\right)$, ordenação de números naturais representados por meio de tabelas $\left(U_{54}\right)$, representação de quantidade por meio de potências de base $10\left(\mathrm{UR}_{110}\right)$, interpretação de gráficos $\left(\mathrm{UR}_{126}\right)$, explicação sobre formação do código de endereçamento postal $\left(\mathrm{UR}_{143}\right)$, relação de equivalência entre escalas termométricas $\left(\mathrm{UR}_{145}\right)$, representação geométrica do número de ouro $\left(\mathrm{UR}_{151}\right)$, etc.

$\mathrm{UR}_{13}$ - (OBM) A calculadora de Juliana é bem diferente. Tem uma tecla $\mathrm{D}$, que duplica o número escrito no visor, e a tecla T, que apaga o algarismo das unidades do número escrito no visor [...]. Suponha que esteja escrito 1999. Se apertarmos D, depois T, em seguida D, depois T, teremos o número? (p. 53)

$\mathrm{UR}_{33}$ - No sinal de entroncamento oblíquo (trânsito), podem ser identificados três ângulos. Com relação a suas medidas esses ângulos são classificados como? (6. ${ }^{\circ}$ ano, p. 150)

$\mathrm{UR}_{40}$ - Público se preocupa mais com o clima. A preocupação do público com o clima triplicou nos últimos seis meses, e dois a cada cinco consumidores querem que os governos limitem as emissões de gases-estufa. [...] Para $16 \%$ dos entrevistados, a mudança climática é uma grande preocupação. O número era apenas $7 \%$ em um levantamento feito em outubro de 2006. (6. ${ }^{\circ}$ ano, p. 218)

$\mathrm{UR}_{46}$ - Sistema métrico decimal. Por muitos séculos os padrões de medidas variavam de um território para outro. No entanto, com a expansão do comércio e o desenvolvimento das ciências, surgiu a necessidade de estabelecer unidades universais, pois padrões diferentes geravam dificuldades e muitas confusões. [...]. Um decreto, assinado na França em 1795, instituiu o chamado sistema métrico decimal (SMD). [...] O Brasil aderiu oficialmente a esse sistema em 1862. (6. ${ }^{\circ}$ ano, p. 238) 
$\mathrm{UR}_{53}$ - Estimativa feita pelo IBGE para a população de capitais de alguns estados brasileiros e do Distrito Federal. Tabela e Gráfico de barras. (7. ${ }^{\circ}$ ano, p. 10)

$\mathrm{UR}_{54}$ - Número de habitantes de algumas capitais brasileiras no ano de 2010. Fonte IBGE (2011). (7. ${ }^{\circ}$ ano, p.11)

$\mathrm{UR}_{109}$ - Na tabela estão indicadas as distâncias aproximadas de alguns planetas em relação ao Sol. Escreva esses números usando a notação científica. ( $8 .^{\circ}$ ano, p. 47$)$

$\mathrm{UR}_{110}$ - O número de glóbulos vermelhos de um adulto é de $2,5 \times 10^{10}$. Escreva esse número na notação decimal. (8. ${ }^{\circ}$ ano, p. 47$)$

$\mathrm{UR}_{126}$ - Gráfico expressando a quantidade de vidro reciclado em diversos países. Abordagem do tema reciclagem. (8..$^{\circ}$ ano, p. 261)

$\mathrm{UR}_{143}-\mathrm{O}$ que é e como funciona o CEP. Mapa do território brasileiro dividido em dez regiões postais numeradas de 0 a $9 .\left(9 .^{\circ}\right.$ ano, p. $\left.89-90\right)$

$\mathrm{UR}_{145}$ - A escala Celsius é uma escala termométrica (termo, em grego, significa calor), criada em 1742 por Anders Celsius (1701-1744). Essa escala baseia-se em dois pontos fixos: o ponto de fusão do gelo-valor zero e o ponto de ebulição da água sob pressão normal-valor 100 (cem). [...]. Podemos citar também a Fahrenheit, criada por Daniel E. Fahrenheit (1686-1736) em 1726. [...]. (9. ${ }^{\circ}$ ano, p. 112)

$\mathrm{UR}_{151}$ - O matemático grego Euclides (325 a. C.- 265 a. C. aproximadamente) propôs uma divisão que tem uma propriedade especial. A razão entre o todo e a maior parte de um segmento é igual a razão entre a maior parte e a menor parte. Dizemos em matemática que o segmento foi dividido na razão áurea. [...]. Geralmente utilizamos uma aproximação para esse número igual a 1,618. [...]. (9. ${ }^{\circ}$ ano, p. 163)

As situações matemáticas associadas à $\mathrm{UT}_{9}$ consistem em atividades que exigem do aluno interpretação e representação numérica no contexto de vários conteúdos, assim como envolvem conhecimento de outras áreas, cujas abordagens procuram promover a contextualização da matemática.

Além disso, constatamos que a contextualização é abordada em todas as seções dos livros da coleção (Desenvolvimento do conteúdo, Seção livre, Vale a pena ler, Exercícios, Desafio, Revisando e Autoavaliação), sendo apresentada, principalmente, para fornecer informações e dados para realização de operações matemáticas, trazendo contextos matemáticos semirreais ${ }^{10}$, mas do cotidiano da sociedade, de outras áreas do conhecimento, como física, literatura, geografia, além de questões referentes à saúde e meio ambiente, como a produção e reciclagem do lixo. Essas reformulações e novas inserções, pelas quais os livros didáticos têm passado e, do mesmo modo, o ensino da matemática como um todo, de acordo com Tomaz e David (2008), pretendem mudar o isolamento e a fragmentação dos conteúdos, já que o conhecimento disciplinar isolado, não favorece a compreensão global da realidade vivida pelos alunos.

Verificamos, ainda, que as tendências abordadas seguem um certo padrão de situações matemáticas como contexto para o desenvolvimento de conteúdos matemáticos. Ou seja,

10 De acordo com Ponte e Quaresma (2012, p. 203), os contextos "podem referir-se a uma "semirealidade" que não existe na vida diária mas é construída, nomeadamente com fins educativos". 
situações que possibilitaram o trabalho com a matemática por meio de elementos que não fossem puramente a operacionalização de cálculos, com vistas a treinar algoritmos.

Por fim, evidenciamos situações, cada qual relacionada a uma ou outra tendência no ensino da matemática, tais como tecnologias, jogos e materiais didáticos, interdisciplinaridade, etnomatemática, mas a contextualização é a tendência predominante, representando $55 \%$ das situações encontradas. Contudo, consideramos que nem todas as propostas envolvendo tendências no ensino da matemática cumprem o papel a elas atribuído, que é promover o ensino da matemática de forma coerente e significativa, apesar do esforço dedicado, caindo na armadilha de se trabalhar com, por exemplo, a Contextualização e a Interdisciplinaridade de forma artificial, servindo simplesmente como ponto de partida para obtenção de dados numéricos, como indicam Tomaz e David (2008).

Entretanto, a intenção dos autores em trazer as tendências para a coleção no intuito de auxiliar nos processos de ensino e de aprendizagem é, com certeza, uma iniciativa relevante para a modificação do ensino da matemática e um passo importante no sentido de aproximar a matemática do aluno, fazendo-o perceber que a matemática é a matemática da vida não só a matemática da escola.

\section{Situações investigativas como cenário de aprendizagem da matemática}

Evidenciamos, também, na coleção um conjunto de situações que consistem em abordagens investigativas para a aprendizagem da matemática neste nível escolar. Em algumas situações as atividades estão voltadas à constituição de dados para atividades de investigação matemática $\left(\mathrm{UR}_{28}\right)$, tal como a situação apresentada no livro do $6^{\circ}$ ano, que propõe uma pesquisa com viés estatístico sobre os pontos positivos e negativos do bairro em que se localiza a escola, promovendo a análise e discussão coletiva destes dados com os alunos. Consideramos que tal abordagem contribui para trazer vivências da realidade do aluno para a sala de aula.

Notamos, ainda, que as situações envolvendo investigações aparecem predominantemente no bloco de conteúdos Tratamento da Informação, o que caracteriza a proposta dos autores em abordar a investigação em atividades envolvendo estatística, leitura, construção e interpretação de gráficos e tabelas.

Identificamos situações relacionadas à apresentação de dados numéricos envolvendo produção de lixo em grandes centros $\left(\mathrm{UR}_{84}\right)$ e registro da quantidade de lixo produzido, cálculo e comparação de percentuais e reflexão sobre reciclagem $\left(\mathrm{UR}_{85}\right)$, o que evidencia uma abordagem desta tendência associada à realização de cálculos a partir de dados estatísticos. 
$\mathrm{UR}_{84}$ - Vamos reciclar o lixo. A natureza leva 4000 anos para decompor completamente o vidro. [...]. As embalagens PET são as grandes vilãs do lixo. (7. ${ }^{\circ}$ ano, p. 134)

$\mathrm{UR}_{85}$ - Observe, durante 1 dia, tudo o que você jogar no lixo. Faça uma estimativa: do lixo que você produziu, qual porcentagem é composta de material reciclável? Compare e discuta sua resposta com os colegas. $\left(7 .^{\circ}\right.$ ano, p. 134$)$

Porém, embora não de maneira tão ampla como na unidade de registro descrita anteriormente $\left(\mathrm{UR}_{28}\right)$, as situações investigativas descritas nestas duas UR promovem a discussão e reflexão em torno de um tema relevante numa dimensão sócio-ambiental, necessitando, portanto, de complementação e construção de reflexões que, por não estarem indicadas no livro didático, ficam a cargo do professor.

Ressaltando a dimensão social da matemática nas situações investigativas evidenciadas na coleção, citamos como exemplo uma proposta de investigação matemática envolvendo coleta, organização, representação e análise de dados e discussão sobre orçamento familiar $\left(\mathrm{UR}_{87}\right)$ no livro do $7^{\circ}$ ano, e uma investigação matemática envolvendo coleta, organização, representação, análise e discussão de dados $\left(\mathrm{UR}_{150}\right)$ no livro do $9^{\circ}$ ano. Tais atividades buscam promover, com os alunos, reflexões sobre as condições socioeconômicas das pessoas.

$\mathrm{UR}_{150}$ - PNAD - Um retrato do Brasil. A PNAD (Pesquisa Nacional por Amostra de Domicílio) tem como objetivo tirar uma fotografia do Brasil que permita analisar as condições de vida do nosso povo: situação de moradia, de saúde, educação e trabalho, por exemplo. A PNAD é uma pesquisa estatística. Seus resultados são obtidos a partir de uma amostra de domicílios. [...] (9. ${ }^{\circ}$ ano, p. 145-148)

Evidenciamos, ainda, situações que se reportam a resolução de problemas. Como exemplo, apresentamos uma situação que propõe a sistematização das etapas da solução de um problema (UR 14$)$. Nesta situação busca-se levar o aluno a propor estratégias de resolução, registrando-as de modo que outras pessoas possam entendê-las, verificar tais estratégias e os resultados encontrados e, por fim, apresentar a resposta ao problema. Este processo aproximase do roteiro para resolução de problemas sugerido por Pólya.

Observamos que, em geral, as abordagens consistem em atividades que devem ser desenvolvidas pelos alunos e estão presentes no Desenvolvimento do conteúdo, seção Exercícios e Seção Livre). A maioria das situações promove a participação ativa do aluno no processo de construção do conhecimento, possibilitando ao aluno visualizar que a matemática oferece elementos que facilitam a análise de outros contextos, inclusive o social e o econômico.

Por fim, poucas situações investigativas que pudessem ser consideradas como pedagogia de projetos foram evidenciadas. As situações investigativas propostas na coleção analisada solicitam atenção e organização do professor, pois, embora abordam temas relevante para a sociedade, oferecem poucos elementos para a discussão e problematização 
em torno destes assuntos e não apresentam indicações de leituras complementares ou outras referências.

Em síntese, a análise sobre o modo como as tendências são abordadas ressalta a importância do professor no processo de construção de conhecimento pelo aluno. O professor, que nas atividades analisadas deixa de exercer um papel central, passa a assumir uma tarefa bastante complicada que consiste em promover a autonomia dos alunos frente à produção e descoberta, ao tempo em que deve acompanhar o processo e sistematizar os resultados obtidos, algo que exige formação adequada e compromisso com a aprendizagem dos alunos.

\section{Algumas compreensões e considerações finais}

A análise da coleção Praticando Matemática, centrada no propósito de identificar quais e analisar como as tendências no ensino da matemática são abordadas, permitiu-nos evidenciar a abordagem de diversas tendências, tais como história da matemática, tecnologias, jogos e materiais didáticos, interdisciplinaridade, pedagogia de projetos, resolução de problemas, etnomatemática e contextualização.

Verificamos, primeiramente, que as tendências são abordadas de forma alternada ou concomitantemente, duas ou mais, ao longo do desenvolvimento dos capítulos dos livros, estando contidas também nas propostas de atividades nas seções de Exercícios, Revisando, Desafios e Autoavaliação, bem como em seções de leitura complementar (Vale a pena ler e Seção livre). No bloco de conteúdos Números e Operações foi evidenciado o maior número de tendências, possivelmente pelo fato de contemplar o maior número de capítulos na coleção.

A frequência que as situações matemáticas associadas às tendências no ensino de matemática são apresentadas evidencia que os processos de ensino e aprendizagem vêm se modificando, aspecto este que até os anos 1980 não se verificava.

Em relação ao modo como as tendências no ensino da matemática são abordadas na coleção, constatamos que as situações contemplam três perspectivas: abordagem histórica para a apresentação e/ou desenvolvimento de conteúdos matemáticos; em situações matemáticas como contexto para o desenvolvimento de conteúdos matemáticos e; em situações investigativas como cenário de aprendizagem da matemática.

Em relação perspectiva associada à abordagem histórica para a apresentação e/ou desenvolvimento de conteúdos matemáticos, evidenciamos um movimento de inserção do contexto histórico de forma coerente, tal como compreendem Miguel e Miorim (2004) e D’Ambrosio (2005). Assim, as abordagens promovidas vêm contribuindo para que o aluno compreenda a matemática como uma manifestação cultural de muitos povos, em vários 
tempos, diversificada, em sua origem e evolução. Embora, muitas das situações apresentadas consitem em contexto para a realização de operações matemáticas.

Relativamente as situações matemáticas que se constituem em contexto para o desenvolvimento de conteúdos matemáticos, nas quais a contextualização é a tendência predominante, destacamos que estas dão conta da sua função, conforme sugerem Tomaz e David (2008), pois caracterizam-se por trazer para a sala de aula problemas que traduzem para a linguagem matemática escolar situações do cotidiano relacionadas ao tema ou conteúdo que está sendo abordado. Em relação a interdisciplinaridade, a análise não nos permitiu evidenciar situações diferenciadas, com contribuições significativas para os processos de ensino e aprendizagem da matemática, pois conforme sugere Lück (1994), a interdisciplinaridade envolve não só a integração dos conteúdos, mas o engajamento dos educadores e o trabalho conjunto. Assim, compreendemos que no âmbito da coleção analisada, esta tendência pode ser considerada somente uma possibilidade, que não necessariamente se concretiza, já que não existe uma indicação no sentido de um trabalho mais amplo, envolvendo conhecimento de outras áreas, deixando a concretização da interdisciplinaridade a cargo do professor.

Sobre as situações que se reportam a resolução de problemas, consideramos que a maioria constitui o que Charnay (1996 apud Flemming, Luz e Mello, 2005) afirma ser utilizado como critério de aprendizagem, em que se parte do simples para o complexo, visualizando um conjunto de partes simples. Também podem ser classificados como resolução de problemas como prática que é destacado por Stanic e Kilpatrick (1989), em que os problemas têm função de prática necessária para reforçar capacidades e conceitos ensinados. Do mesmo modo, ao considerar a definição de problema apresentada por Onuchic (1999), os demais problemas apresentados na coleção não podem ser compreendidos dentro da tendência resolução de problemas, pois muitas das situações solicitam ao aluno apenas aplicar uma fórmula ou uma determinada técnica operatória, que dificilmente utilizará para resolver outros problemas, sem que construa um campo de conceitos que tomam sentido num campo de problemas.

Portanto, a análise sobre o modo como as tendências são abordadas nos livros evidencia a preocupação com ensino da matemática, a medida que os autores procuram tornar os temas da matemática acessíveis ao aluno, inserindo-os em contextos que aproximam a matemática das suas vivências, e desenvolvendo-nos em situações que envolvem problemas.

No que diz respeito às situações investigativas como cenário de aprendizagem da matemática, destacamos que as atividades, tais como aquelas envolvendo à questão do lixo, a investigação proposta necessita de uma atenção especial do professor para que de fato possa 
ser mais aprofundada. A intervenção do professor é fundamental, ainda, para promover o envolvimento do aluno, incluindo à produção de dados para realização de cálculos e ao tratamento da informação, a transformação da informação em conhecimento próprio, como pontuam Hernández e Ventura (1998). Salientamos, porém, que algumas das tendências identificadas como conectadas ao conteúdo, não oferecem possibilidades de abordagem mais ampla, pois apresentam contextos ou fornecem dados para realização de operações matemáticas, limitando, desta forma, o potencial das tendências no ensino da matemática, não cumprindo o papel de orientar os processos de ensino e de aprendizagem.

Um aspecto positivo evidenciado nesta perspectiva é a valorização da função social da matemática. A coleção busca evidenciar a participação da matemática na sociedade, abordando questões que envolvem sua participação direta no cotidiano das pessoas e, também, situações em que a matemática serve de elemento auxiliar na compreensão de contextos sociais relacionados ao meio ambiente, saúde, economia.

Acreditamos, portanto, que os processos de formação docente precisam contemplar, além da compreensão sobre conteúdo a ser ministrado pelo professor, reflexões sobre eventos sociais, políticos, econômicos e culturais que influenciam os processos educativos, bem como as concepções sobre educação, ensino, papel do professor e, avançando um pouco mais, possibilitem a reflexão sobre a prática. Nesta perspectiva, a função do professor é fundamental para o desenvolvimento da educação, de modo que solicita atenção especial do poder público, assim como requer políticas públicas específicas e adequadas, as quais possam oportunizar ao professor o desenvolvimento de conhecimentos, autonomia profissional e valorização social.

Esclarecemos, por fim, que a discussão produzida não esgota o debate em torno da temática, seja em relação à análise de livros didáticos de matemática ou à presença das tendências no ensino da matemática ou ao modo como são abordadas. Estes são temas que demandam novos estudos e discussões.

\section{Referências}

BARDIN, Laurence. Análise de Conteúdo. 5. ed. Lisboa: Edições 70, 2014.

BITTENCOURT, Circe Maria Fernandes. Autores e editores de compêndios e livros de leitura (1810-1910). Educação e Pesquisa, São Paulo, v. 30, n. 3, p. 475-491, set./dez. 2004. Disponível em: <http://www.scielo.br/pdf/ep/v30n3/a08v30n3.pdf>. Acesso em: 12 dez. 2014.

BORBA, Marcelo de Carvalho; PENTEADO, Miriam Godoy. Informática e Educação Matemática. Belo Horizonte: Autêntica, 2001. 
BRASIL. Parâmetros Curriculares Nacionais: Matemática/1998. Disponível em: $<$ http://portal.mec.gov.br/seb/arquivos/pdf/matematica.pdf $>$. Acesso em: 05 jan. 2015.

BRASIL. Lei $\mathrm{n}^{\circ} 11.274$, de 6 de fevereiro de 2006. Altera a redação dos arts. 29, 30, 32 e 87 da Lei n. 9.394, de 20 de dezembro de 1996, que estabelece as diretrizes e bases da educação nacional, dispondo sobre a duração de 9 (nove) anos para o ensino fundamental, com matrícula obrigatória a partir dos 6 (seis) anos de idade. Diário Oficial da União, Brasília, DF, 07 de fevereiro de 2006. Disponível em: $<$ http://www.planalto.gov.br/ccivil_03/_Ato2004-2006/2006/Lei/L11274.htm>. Acesso em: 11 mar. 2014.

D’AMBROSIO, Beatriz Silva. Conteúdo e metodologia na formação de professores. In: FIORENTINI, Dario; NACARATO, Adair Mendes (orgs). Cultura, formação e desenvolvimento profissional de professores que ensinam matemática. São Paulo: Musa Editora, 2005.

D’AMBROSIO, Ubiratan. Etnomatemática: elo entre as tradições e a modernidade. Belo Horizonte: Autêntica, 2002.

D’AMBROSIO, Ubiratan. Uma história concisa da matemática no Brasil. Petrópolis: Vozes, 2008.

EVANGELISTA, Antônia Dinamária Gomes. Regras matemáticas e suas justificativas: breve histórico sobre o ensino de matemática no Brasil e uma reflexão acerca da inclusão de demonstrações na prática docente. 2014. 101 f. Dissertação (Mestrado em Matemática) Universidade Federal do Ceará, Juazeiro do Norte, 2014.

FLEMMING, Diva Marília; LUZ, Elisa Flemming; MELlO, Ana Cláudia Collaço de. Tendências em Educação Matemática. 2. ed. Palhoça: UnisulVirtual, 2005. Disponível em: $<$ http://busca.unisul.br/pdf/89279_Diva.pdf>. Acesso em: 07 ago. 2015.

GRANDO, Regina Célia. O Jogo suas Possibilidades Metodológicas no Processo EnsinoAprendizagem da Matemática. 1995. 193 f. Dissertação (Mestrado em Educação) Universidade Estadual de Campinas, Campinas, 1995.

HERNÁNDEZ, Fernando; VENTURA, Montserrat. A organização do currículo por projetos de trabalho: o conhecimento é um caleidoscópio. 5. ed. Porto Alegre: Artmed, 1998.

LIMA, Elicio Gomes. Para compreender o livro didático como objeto de pesquisa. Educação e Fronteiras On-Line, Dourados/MS, v. 2, n. 4, p. 143-155, jan/abr. 2012. Disponível em: <file://C:/Users/Usu\%C3\%A1rio/Downloads/1563-4357-1-PB.pdf>. Acesso em: 02 mar. 2015.

LÜCK, Heloisa. Pedagogia interdisciplinar: fundamentos teórico-metodológicos. Petrópolis: Vozes, 1994.

MALHEIROS, Ana Paula dos Santos. Modelagem matemática e pedagogia de projetos: possíveis interseções. In: Encontro Nacional de Educação Matemática, Belo Horizonte. Anais... Belo Horizonte, 9., 2007. Disponível em: $<\mathrm{http} / /$ www.sbembrasil.org.br/files/ix_enem/Comunicacao_Cientifica/Trabalhos/CC2594174 5800T.rtf $>$. Acesso em: 17 out. 2015.

MIGUEL, Antonio; MIORIM, Maria Ângela. História na Educação Matemática: propostas e desafios. Belo Horizonte: Autêntica, 2004. 
OLIVEIRA, Esmeralda Maria Queiroz de. O uso do livro didático de matemática por professores do ensino fundamental. 2007. 152 f. Dissertação (Mestrado em Educação) Universidade Federal de Pernambuco, Recife, 2007.

ONUCHIC, Lourdes de La Rosa. Ensino-Aprendizagem de Matemática através da resolução de problemas. In: Bicudo, Maria Aparecida Viggiani. Pesquisa em Educação Matemática: Concepção \& Perspectivas. São Paulo: UNESP, 1999.

PÓLYA, George. A arte de resolver problemas: um novo aspecto do método matemático. Rio de Janeiro: Interciência, 1978.

PONTE, João Pedro da; QUARESMA, Marisa. O papel do contexto nas tarefas matemáticas. Interacções, n. 22, 2012, p. 196-216. Disponível em: <http://www.eses.pt/interaccoes>. Acesso em: 14 maio 2016.

PRADO, Maria Elisabette Brisola Britto. Pedagogia de Projetos: fundamentos e implicações. In: AMEIDA, Maria Elizabeth Bianconcini de; MORAN, José Manuel (Org.). Integração das tecnologias na educação. Brasília: Ministério da Educação/SEED/TV Escola/Salto para o Futuro, 2005. cap. 1, artigo 1.1, p. 12-17. Disponível em: $<$ http://www.tvebrasil.com.br/salto $>$. Acesso em: 16 nov. 2015.

ROMANATTO, Mauro Carlos. O livro didático: alcances e limites. In: Encontro Paulista de Matemática, v. 7, 2004. Disponível em: <https://scholar.google.com.br/scholar?hl=pt$\mathrm{BR} \& \mathrm{q}=$ criticas $+\mathrm{ao}+$ livro $+\mathrm{did} \% \mathrm{C} 3 \% \mathrm{~A} 1 \mathrm{tico}+\mathrm{de}+$ matem $\% \mathrm{C} 3 \% \mathrm{~A} 1 \mathrm{tica} \& \mathrm{btnG}=\& 1 \mathrm{r}>$. Acesso em: 05 jan. 2015.

ROMANATTO, Mauro Carlos. Resolução de problemas nas aulas de Matemática. Revista Eletrônica de Educação. São Carlos: UFSCar, v. 6, n. 1, p.299-311, mai. 2012. Disponível em: $<$ http://www.reveduc.ufscar.br>. Acesso em: 20 jun. 2015.

STANIC, Georg M. A.; KILPATRICK, Jeremy. (1989). Historical perspectives on problem solving in the mathematics curriculum. In: R. I. Charles \& E. A. Silver (Eds.). The teaching and assessing of mathematical problem solving (p. 01-22). Reston, VA: NCTM e Lawrence Erlbaum.

TOMAZ, Vanessa Sena; DAVID, Maria Manuela M. S. Interdisciplinaridade e a aprendizagem da matemática em sala de aula. Belo Horizonte: Autêntica, 2008.

VALENTE, Wagner Rodrigues. Osvaldo Sangiorgi: um professor moderno. São Paulo: Annablume, 2008.

VORPAGUEL, Kari Simone. Livro Didático de Matemática: perspectivas de sua criação pelos autores. 2008. 246 f. Dissertação (Mestrado em Educação) - Universidade Federal do Paraná, Curitiba, 2008. 